OPEN ACCESS

Edited by:

Yongjun Sun,

Hebei University of Science and

Technology, China

Reviewed by:

Zhouqing Chen,

Soochow University, China Amit Kumar,

Rajendra Institute of Medical

Sciences, India

*Correspondence:

Jianyong $\mathrm{J}$

jijianyong2005@163.com

Wenqiang Xin

xinwenqiangdr@126.com

${ }^{+}$These authors have contributed equally to this work and share first

authorship

Specialty section: This article was submitted to

Neuropharmacology,

a section of the journal

Frontiers in Pharmacology

Received: 16 October 2021 Accepted: 24 January 2022

Published: 25 February 2022

Citation:

Pan Y, Zhao Z, Yang T, Jiao Q, Wei W, Ji J and Xin W (2022) A Meta-Analysis of Using Protamine for Reducing the Risk of Hemorrhage During Carotid Recanalization: Direct Comparisons of

Post-operative Complications.

Front. Pharmacol. 13:796329.

doi: 10.3389/fphar.2022.796329

\section{A Meta-Analysis of Using Protamine for Reducing the Risk of Hemorrhage During Carotid Recanalization: Direct Comparisons of Post-operative Complications}

\author{
Yongli Pan ${ }^{1 \dagger}$, Zhiqiang Zhao ${ }^{2 \dagger}$, Tao Yang ${ }^{2 \dagger}$, Qingzheng Jiao ${ }^{3}$, Wei Wei ${ }^{4}$, Jianyong $\mathrm{Ji}^{5+\star}$ and \\ Wenqiang $\mathrm{Xin}^{6 *}$
}

${ }^{1}$ Department of Neurology, Weifang Medical University, Weifang, China, ${ }^{2}$ Department of Neurosurgery, Heji Hospital Affiliated Changzhi Medical College, Changzhi, China, ${ }^{3}$ Second Department of Internal Medicine, Gucheng Country Hospital, Shijiazhuang, China, ${ }^{4}$ Department of Neurology, Mianyang Central Hospital, Mianyang, China, ${ }^{5}$ Department of Neurosurgery, Liaocheng People's Hospital, Liaocheng, China, ${ }^{6}$ Department of Neurosurgery, Tianjin Medical University General Hospital, Tianjin, China

Background: Protamine can decrease the risk of hemorrhage during carotid recanalization. However, it may cause severe side effects. There is no consensus on the safety and efficacy of protamine during surgery. Thus, we conduct a comprehensive review and meta-analysis to compare the differences between the protamine and the noprotamine group.

Method: We systematically obtained literature from Medline, Google Scholar, Cochrane Library, and PubMed electronic databases. All four databases were scanned from 1937 when protamine was first adopted as a heparin antagonist until February 2021. The reference lists of identified studies were manually checked to determine other eligible studies that qualify. The articles were included in this meta-analysis as long as they met the criteria of PICOS; conference or commentary articles, letters, case report or series, and animal observation were excluded from this study. The Newcastle-Ottawa Quality Assessment Scale and Cochrane Collaboration's tool are used to assess the risk of bias of each included observational study and RCT, respectively. Stata version 12.0 statistical software (StataCorp LP, College Station, Texas) was adopted as statistical software. When $l^{2}<50 \%$, we consider that the data have no obvious heterogeneity, and we conduct a meta-analysis using the fixed-effect model. Otherwise, the random-effect model was performed.

Result: A total of 11 studies, consisting of 94,618 participants, are included in this study. Our analysis found that the rate of wound hematoma had a significant difference among protamine and no-protamine patients $(\mathrm{OR}=0.268,95 \% \mathrm{Cl}=0.093$ to $0.774, p=0.015)$. Furthermore, the incidence of hematoma requiring re-operation $(0.7 \%)$ was significantly

Abbreviations: CEA, Carotid endarterectomy; CAS, Carotid artery stenting; MI, Myocardial Infarction; RDs, Risk differences; ORs, Odds ratios; FDA, Food and Drug Administration; CIs, Confidence Intervals; RCTs, Randomized Controlled Trials; TIA, Transient Ischemic Attacks. 
lower than that of patients without protamine (1.8\%). However, there was no significant difference in the incidence of stroke, wound hematoma with hypertension, transient ischemic attacks (TIA), myocardial infarction (MI), and death.

Conclusion: Among included participants undergoing recanalization, the use of protamine is effective in reducing hematoma without increasing the risk of having other complications. Besides, more evidence-based performance is needed to supplement this opinion due to inherent limitations.

Keywords: protamine, carotid recanalization, meta-analysis, carotid stenosis, hemorrhage - cerebral

\section{INTRODUCTION}

Ischemic stroke accounts for the mortality of approximately more than ten million lives per year all over the world (Yip et al., 2016), and it is an important public health concern. Considerable research evidence demonstrates that the prevalence of carotid stenosis is about 7\% (Dharmakidari et al., 2017), which is becoming an important public health issue (Abbott et al., 2015). Carotid endarterectomy (CEA), performed to prevent embolus, is considered a conventional treatment (Howell, 2007). Carotid artery stenting (CAS), a minimally invasive procedure (Spiliopoulos et al., 2019), has emerged as an effective treatment modality for carotid artery stenosis (Setacci et al., 2018). Although these two surgical interventions have improved the prognosis of ischemic stroke, they may carry hemorrhage as a severe complication (Spence et al., 2016). Heparin is a robust anticoagulant used routinely during both CEA and CAS surgeries to avoid thromboembolic complications (Lynch and Kavanagh, 2016; Sokolowska et al., 2016). After such surgeries, some surgeons advocate the adoption of protamine to achieve a systemic anticoagulant effect to decrease the risk of hemorrhage (Liang et al., 2021). Protamine is known to be arginine-rich, making it a positively charged protein (Bakchoul et al., 2016), and is an approved drug by the Food and Drug Administration (FDA). Despite its neutralization action, protamine may cause severe side effects such as systemic hypotension, anaphylactic reaction, pulmonary hypertension, and tissue damage of the lungs, kidneys, and red blood cells (Sokolowska et al., 2016). Hence, the use of protamine can have a significant difference in short-term and long-term morbidity and mortality (Al-Kassou et al., 2020). As one study reviewed 10,059 CEAs performed in 9,260 patients from 2003 to 2012, protamine use remained stable from 2003 through 2007 at $43 \%$. Then, there was a significant increase in protamine use to $52 \%$ from the beginning in January 2008 (Patel et al., 2013). Theoretically, protamine can bind with the glucosaminoglycan of heparin to form a stable complex, which, in turn, suppresses the activity of antithrombin, herein counteracting the anticoagulant effect of heparin and achieving the effect of hemostasis. Some surgeons advocate the routine use of protamine to minimize bleeding complications, whereas some others avoid heparin reversal to minimize the risk of stroke through thrombus formation on the endarterectomy surface of the artery (Cho et al., 2012).
Therefore, the purpose of this study is to evaluate the safety and efficacy of protamine to reduce the risk of hemorrhage during carotid recanalization.

\section{MATERIALS AND METHODS}

\section{Literature Search Strategy}

We systematically obtained literature from Medline, Google Scholar, Cochrane Library, and PubMed electronic databases. We utilized controlled vocabulary to build the search terms such as the National Library of Medicine in this study. All four databases were scanned from 1937 when protamine was first adopted as a heparin antagonist until February 2021 for the keywords of protamine, carotid endarterectomy, and carotid artery stenosis in combination with Boolean logic (Jaques, 1973). The specific search strategy is shown in Table 1. After the original search, the relevant studies and their references were searched manually by two authors. Beyond that, all references to previous reviews and related clinical trials were manually checked to identify potential publications that were not included in our electronic search results.

\section{Inclusion and Exclusion Criteria}

Studies are considered eligible if they fulfilled the predefined inclusion criteria: (1) population: participant with carotid stenosis; (2) intervention: all patients strictly undergoing carotid recanalization; (3) comparison intervention: use of protamine to no-protamine group; (4) outcome measures: one or more of the following outcomes were reported: complications of wound hematoma, hematoma requiring re-operation, wound hematoma with hypertension, transient ischemic attacks (TIA), myocardial infarction (MI), stroke, and death; and (5) official published prospective and retrospective studies in English.

The exclusion criteria are listed as follows: (1) conference or commentary articles and letters, (2) atypical patients and outcome data, (3) case report and case series, and (4) animal observation.

\section{Data Extraction and Outcome Measures}

Data were extracted by using a form prepared in advance and from the eligible researchers. Each relevant study was independently captured by two authors for the following essential details: the first author of the study, publication year, type of study, quality assessment, endpoints, and study 
TABLE 1 | The specific search strategy.

Carotid stenosis OR carotid artery stenosis OR carotid disease OR carotid artery disease

AND

CAS OR carotid artery stenting OR carotid angioplasty OR carotid stenting OR CEA OR carotid endarterectomy OR endarterectomy OR carotid surgery OR carotid revascularization

AND

Protamine

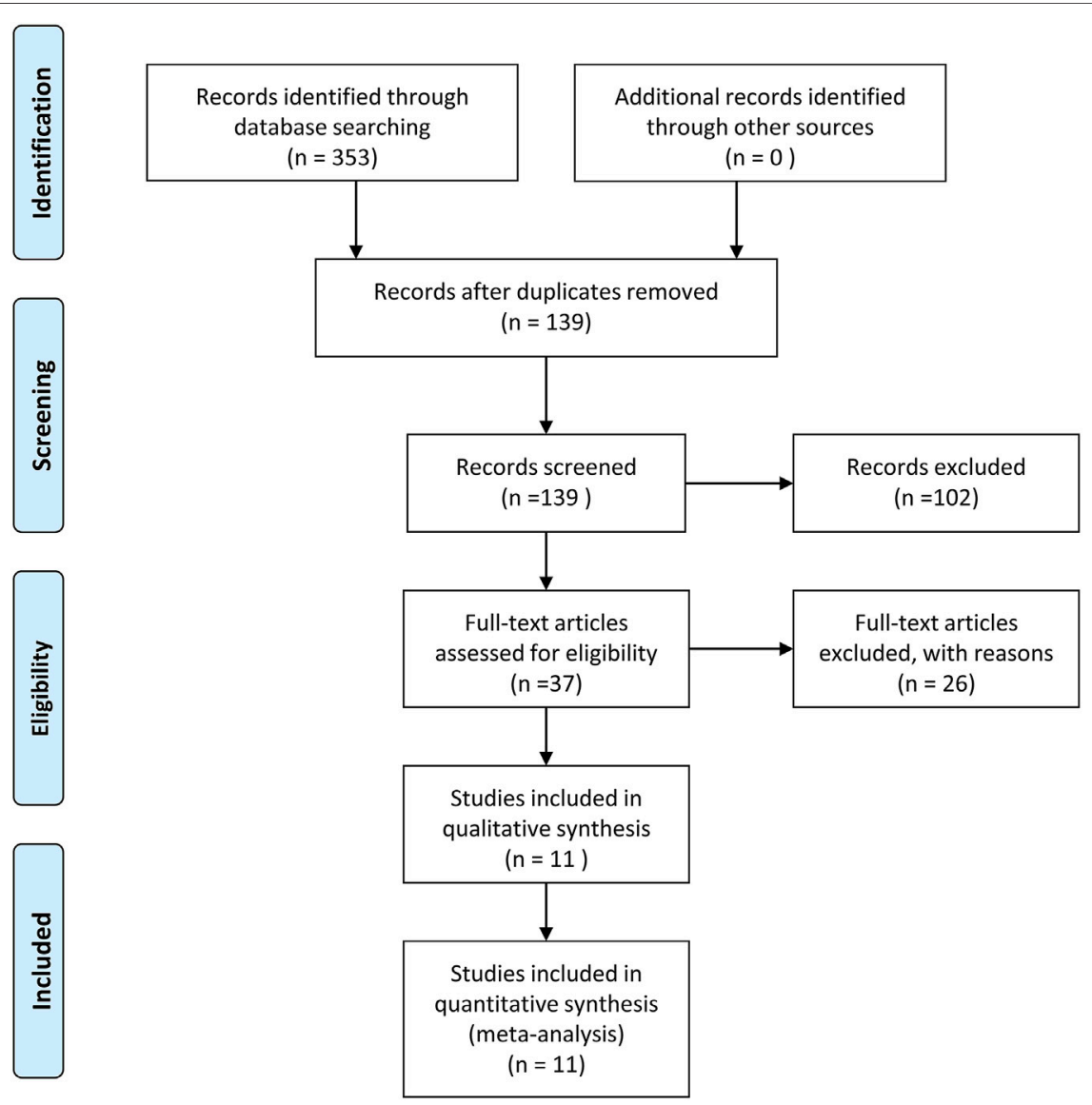

FIGURE 1 | Flowchart of the study selection process.

characteristics including the number of populations in total, mean age, and gender ratio, among others. All disagreements were discussed until a final decision is reached. The primary study endpoint measurements are relevant to hemorrhagic damage including wound hematoma, hematoma requiring reoperation, and hematoma with hypertension, and secondary endpoints were the composite of ischemic injuries including stroke, TIA, and MI. Herein, in primary endpoints, all hematoma was defined as wound hematoma. In secondary endpoints, stroke was defined as 1 or more of the following: (1) an increase in the National Institute of Health stroke scale (NIHSS) score of $>4$ points from pre-stroke score; (2) an increase in the MRS score of $>2$ points from the pre-stroke score; or (3) stroke leading to a modified Rankin scale (MRS) score of 5 or more.

\section{Statistical Analysis}

Stata version 12.0 statistical software (StataCorp LP, College Station, Texas) was adopted as statistical software. The risk differences (RDs) or odds ratios (ORs) with the corresponding 95\% confidence intervals ( $95 \%$ CIs) were used as measures of the treatment effect of protamine. We accessed the heterogeneity with the Higgins $I$-square $\left(I^{2}\right)$, which indicated the percentage of the observed between-study viability. $I^{2}$ over $25 \%$ and less than $75 \%$ was considered as moderately heterogeneous or significant heterogeneity. If $I^{2}$ was under $50 \%$, the endpoint item was 
TABLE 2 | Characteristics of publication year, country, study type, cases, general anesthesia, and mean age in each group for included studies.

\begin{tabular}{|c|c|c|c|c|c|c|c|c|}
\hline \multirow[t]{2}{*}{ Study } & \multirow[t]{2}{*}{ Years } & \multirow[t]{2}{*}{ Country } & \multirow[t]{2}{*}{ Study design } & \multirow[t]{2}{*}{ General anesthesia } & \multicolumn{2}{|c|}{ Sample size } & \multicolumn{2}{|c|}{ Mean age (Years) } \\
\hline & & & & & Protamine & No protamine & Protamine & No protamine \\
\hline \multicolumn{9}{|c|}{ Protamine use in carotid endarterectomy (CEA) } \\
\hline Treiman et al. & 1990 & United States & Non-RCT & $100 \%$ & 328 & 369 & 71 & 71 \\
\hline Mauney et al. & 1995 & United States & Non-RCT & $98.3 \%$ & 193 & 155 & 65.9 & 68.8 \\
\hline Fearn et al. & 1997 & United Kingdom & $\mathrm{RCT}$ & $100 \%$ & 31 & 33 & 66 & 61.9 \\
\hline Levison, et al. & 1999 & United States & Non-RCT & NA & 365 & 42 & 70.6 & 69 \\
\hline Dellagrammaticas et al. & 2008 & United Kingdom & $\mathrm{RCT}$ & $50 \%$ & 594 & 1,513 & 70 & 70.4 \\
\hline Stone et al. & 2010 & United States & Non-RCT & $50 \%$ & 2,087 & 2,500 & 69.2 & 70 \\
\hline Mazzalai et al. & 2014 & Italy & Non-RCT & $100 \%$ & 201 & 1,294 & 75.7 & 75.1 \\
\hline Stone et al. & 2020 & United States & Non-RCT I & $100 \%$ & 53,349 & 23,966 & $70.0 \pm 9.1$ & $69.1 \pm 9.2$ \\
\hline \multicolumn{9}{|c|}{ Protamine use in carotid artery stenting (CAS) } \\
\hline Mcdonald et al. & 2013 & United States & Non-RCT & NA & 555 & 555 & NA & NA \\
\hline Liang et al. & 2020 & United States & Non-RCT & NA & 944 & 944 & $72.7 \pm 9.7$ & $73.2 \pm 9.4$ \\
\hline Liang et al. & 2021 & United States & Non-RCT & NA & 2,300 & 2,300 & $70.6 \pm 9.5$ & $70.4 \pm 9.7$ \\
\hline
\end{tabular}

Note: NA: not available; RCT, randomized controlled trials.

considered to be homogeneous, and we ran a meta-analysis by using a fixed-effect model according to the Cochrane Handbook for Systematic Reviews of Interventions. Otherwise, the randomeffect model was performed.

\section{Quality of Evidence Assessment}

We used the guidance from the Grading of Recommendations Assessment, Development and Evaluation (GRADE) working group to assess the quality of evidence for the primary outcome (Li et al., 2019). The GRADE summary of findings table was produced using the GradePRO software.

\section{RESULTS}

\section{Search Result}

The screening process is displayed in Figure 1, which is based on the inclusion and exclusion criteria. The search initially yielded a total of 353 articles. After the exclusion of duplicated or irrelevant articles, 139 eligible studies were enrolled in this study. Later, after evaluating the full text of the remaining articles, 37 articles met our inclusion criteria. Finally, 11 studies were involved in our quantitative synthesis.

\section{Characteristics of Included Studies}

Detailed characteristics of the 11 observational articles, including 94,618 participants (median sample size, 1,495; range, 64 to 77,315 ) with an average age of 76 years (range, 59.1 to 82.6), are listed in Table 2. The majority of studies were performed in the United States (Liang et al., 2021; Treiman et al., 1990; Stone et al., 2010; Stone et al., 2020; McDonald et al., 2013; Liang et al., 2020). Two were in the United Kingdom (Fearn et al., 1997; Dellagrammaticas et al., 2008), and another one was from Italy (Mazzalai et al., 2014). There were 9 Non-RCTs (Randomized Controlled Trials) (Liang et al., 2021; Treiman et al., 1990; Stone et al., 2010; Stone et al., 2020; McDonald et al., 2013; Liang et al., 2020; Mazzalai et al., 2014; Mauney et al., 1995) ( $n=92,447)$ and 2 RCTs (Fearn et al., 1997; Dellagrammaticas et al., 2008) involving 2,171 patients randomized to either protamine of heparin or not restrictedly undergoing CEA. In the protamine group, out of the 60,947 patients, 57,148 were allocated to CEA, and 3,799 were from CAS, with an average age from 65.9 to 79.1 years old. In the no protamine group, $57.8 \%$ of enrolled participants were from CEA. Nearly all surgeries considered age, whereas only McDonald et al. (2013) ignored this.

\section{Quality Assessment}

Methodological quality and risk of bias in the included observational studies are assessed by two reviewers independently by using the Newcastle-Ottawa Quality Assessment Scale (Mitchell-Jones et al., 2017), which consists of three main categories: selection, comparability, and outcome, with questions in each area corresponding to the study quality (Newhall et al., 2016). The evaluation scores for all non-RCT are listed in Table 3 with the highest quality of 9 points. Studies that scored lower than 5 points equate to low quality, and a score of 6-7 points is regarded as moderate quality. Additionally, the Cochrane Collaboration's tool is used for assessing the risk of bias of each included RCT. The results of the quality assessment of RCT are provided in Table 4.

\section{The Outcome of the Meta-Analysis}

There were nearly ten thousand participants, $92 \%$ of whom have been undergoing CEA and $8 \%$ had been treated with CAS. The detailed results and GRADE assessment of outcomes are shown in Table 5.

\section{Wound Hematoma}

We include four independent pieces of research of CEA with 4,706 patients (1,488 of protamine and 3,218 of no-protamine). Among these studies, the incidence of wound hematoma in the protamine group is $3.8 \%$ (57 of 1,488), which is smaller than the no-protamine group $(9.5 \%, 305$ of 3,218$)$. This comparison fully indicates that the group of protamine is associated with a significantly lower incidence of wound hematoma than participants treated with non-protamine $(\mathrm{OR}=0.268,95 \% \mathrm{CI}=0.093$ to $0.774, p=0.015$, Figure 2$)$. Similarly, in the subgroup of CEA, the results are the same. However, a significant heterogeneity was observed $\left(I^{2}=77.2 \%, p=0.004\right)$. A 
TABLE 3 | The quality assessment in randomized controlled trials.

\begin{tabular}{|c|c|c|c|c|c|}
\hline \multirow[t]{2}{*}{ Author, year } & \multirow[t]{2}{*}{ Design } & \multicolumn{4}{|c|}{ Newcastle-Ottawa scale (NOS) } \\
\hline & & Selection & Comparability & Exposure & Total score \\
\hline Treiman et al. 1990 & Non-RCT & 3 & 1 & 3 & 7 \\
\hline Mauney et al. 1995 & Non-RCT & 3 & 2 & 3 & 8 \\
\hline Levison, et al. 1999 & Non-RCT & 3 & 2 & 2 & 7 \\
\hline Stone et al. 2010 & Non-RCT & 3 & 2 & 2 & 7 \\
\hline Mazzalai et al. 2014 & Non-RCT & 4 & 1 & 3 & 8 \\
\hline Stone et al. 2020 & Non-RCT & 4 & 2 & 2 & 8 \\
\hline Mcdonald et al. 2013 & Non-RCT & 3 & 2 & 3 & 8 \\
\hline Liang et al. 2020 & Non-RCT & 3 & 1 & 3 & 7 \\
\hline Liang et al. 2021 & Non-RCT & 4 & 2 & 2 & 8 \\
\hline
\end{tabular}

Note: NOS , Newcastle-Ottawa scale.

TABLE 4 | Cochrane Collaboration's tool for quality assessment in randomized controlled trials.

\begin{tabular}{|c|c|c|c|c|c|c|}
\hline Trials & Sequence generation & $\begin{array}{c}\text { Allocation } \\
\text { concealment }\end{array}$ & $\begin{array}{c}\text { Blinding of } \\
\text { outcome assessors }\end{array}$ & $\begin{array}{c}\text { Incomplete outcome } \\
\text { data }\end{array}$ & $\begin{array}{l}\text { Selective outcome } \\
\text { reporting }\end{array}$ & Others \\
\hline Fearn et al. 1997 & Low & Unclear & Low & Low & Low & Low \\
\hline Dellagrammaticas et al. 2008 & Low & Low & Low & Low & Low & Unclear \\
\hline
\end{tabular}

TABLE 5 | The post-operative outcomes of this meta-analysis. The bold values refer to $p$-value $<0.05$.

\begin{tabular}{|c|c|c|c|c|c|c|c|c|c|}
\hline \multirow[t]{2}{*}{ Outcomes } & \multirow{2}{*}{$\begin{array}{c}\text { Study } \\
\text { numbers }\end{array}$} & \multicolumn{2}{|c|}{ Event rates } & \multicolumn{3}{|c|}{ Overall effect } & \multicolumn{2}{|c|}{ Heterogeneity } & \multirow{2}{*}{$\frac{E Q}{(G R A D E)}$} \\
\hline & & Protamine & No protamine & $\begin{array}{c}\text { Effect } \\
\text { estimates }\end{array}$ & $95 \% \mathrm{Cls}$ & $p$-Value & $I^{2}(\%)$ & $p$-Value & \\
\hline \multicolumn{10}{|c|}{ The use of protamine in carotid recanalization } \\
\hline Wound hematoma $(\mathrm{WH})$ & 4 & $57 / 1,488$ (3.83\%) & $305 / 3,218$ (9.48\%) & OR (0.268) & $0.093-0.774$ & 0.015 & 77.2 & 0.004 & Low \\
\hline $\begin{array}{l}\text { WH requiring re- } \\
\text { operation }\end{array}$ & 8 & $\begin{array}{c}409 / \\
60,013(0.68 \%)\end{array}$ & $\begin{array}{c}591 / \\
32,714(1.81 \%)\end{array}$ & OR $(0.475)$ & $0.282-0.798$ & 0.005 & 77.3 & 0.000 & Low \\
\hline WH with hypertension & 3 & $\begin{array}{c}170 / 1,471 \\
(11.56 \%)\end{array}$ & $\begin{array}{r}347 / 2,607 \\
(13.31 \%)\end{array}$ & OR (0.704) & $0.358-1.388$ & 0.311 & 76.0 & 0.015 & Low \\
\hline $\begin{array}{l}\text { Transient Ischemic } \\
\text { Attacks }\end{array}$ & 5 & $50 / 4,193(1.19 \%)$ & $91 / 5,248(1.73 \%)$ & OR $(0.793)$ & $0.546-1.151$ & 0.222 & 44.4 & 0.126 & Low \\
\hline Myocardial Infarction & 7 & $\begin{array}{c}430 / \\
60,030(0.72 \%)\end{array}$ & $\begin{array}{c}245 / \\
33,072(0.74 \%)\end{array}$ & OR $(0.935)$ & $0.797-1.096$ & 0.408 & 0.0 & 0.446 & High \\
\hline Post-operative Stroke & 10 & $\begin{array}{c}735 / \\
60,916(1.21 \%)\end{array}$ & $\begin{array}{c}426 / \\
33,638(1.27 \%)\end{array}$ & OR (1.071) & $0.944-1.214$ & 0.286 & 30.1 & 0.168 & Low \\
\hline Post-operative Death & 7 & $\begin{array}{c}138 / \\
56,638(0.24 \%)\end{array}$ & $82 / 30,526(0.36 \%)$ & $\mathrm{RD}(0.000)$ & $-0.001-0.001$ & 0.877 & 0.0 & 0.719 & Low \\
\hline \multicolumn{10}{|c|}{ The use of protamine in CEA } \\
\hline Wound hematoma $(\mathrm{WH})$ & 4 & $57 / 1,488$ (3.83\%) & $305 / 3,218(9.48 \%)$ & OR (0.268) & $0.093-0.774$ & 0.015 & 77.2 & 0.004 & Low \\
\hline $\begin{array}{l}\text { WH requiring re- } \\
\text { operation }\end{array}$ & 6 & $\begin{array}{c}379 / \\
56,769(0.67 \%)\end{array}$ & $\begin{array}{c}546 / \\
29,470(1.85 \%)\end{array}$ & OR $(0.429)$ & $0.265-0.694$ & 0.001 & 61.0 & 0.025 & Low \\
\hline WH with hypertension & 2 & $22 / 527(4.17 \%)$ & $\begin{array}{c}209 / 1,663 \\
(12.57 \%)\end{array}$ & OR (0.333) & $0.057-1.959$ & 0.224 & 67.6 & 0.079 & Low \\
\hline $\begin{array}{l}\text { Transient Ischemic } \\
\text { Attacks }\end{array}$ & 2 & 3/394 (0.76\%) & $41 / 1,449(2.83 \%)$ & OR $(0.255)$ & $0.068-0.947$ & 0.041 & 0.0 & 0.366 & High \\
\hline Myocardial Infarction & 4 & $\begin{array}{c}399 / \\
56,231(0.71 \%)\end{array}$ & $\begin{array}{c}222 / \\
29,273(0.76 \%)\end{array}$ & OR (0.902) & $0.764-1.065$ & 0.224 & 0.0 & 0.661 & High \\
\hline Post-operative Stroke & 7 & $\begin{array}{c}641 / \\
57,117(1.12 \%)\end{array}$ & $\begin{array}{c}354 / \\
29,839(1.19 \%)\end{array}$ & OR (1.029) & $0.897-1.180$ & 0.687 & 37 & 0.146 & Low \\
\hline Post-operative Death & 4 & $\begin{array}{c}106 / \\
52,839(0.20 \%)\end{array}$ & $54 / 26,727$ (0.20\%) & RD (0.000) & $-0.001-0.001$ & 0.878 & 0.0 & 0.967 & High \\
\hline
\end{tabular}

Note. Cls, confidence intervals; $R D$, risk difference; $O R$, odds ratio; $E Q$, evidence quality. 


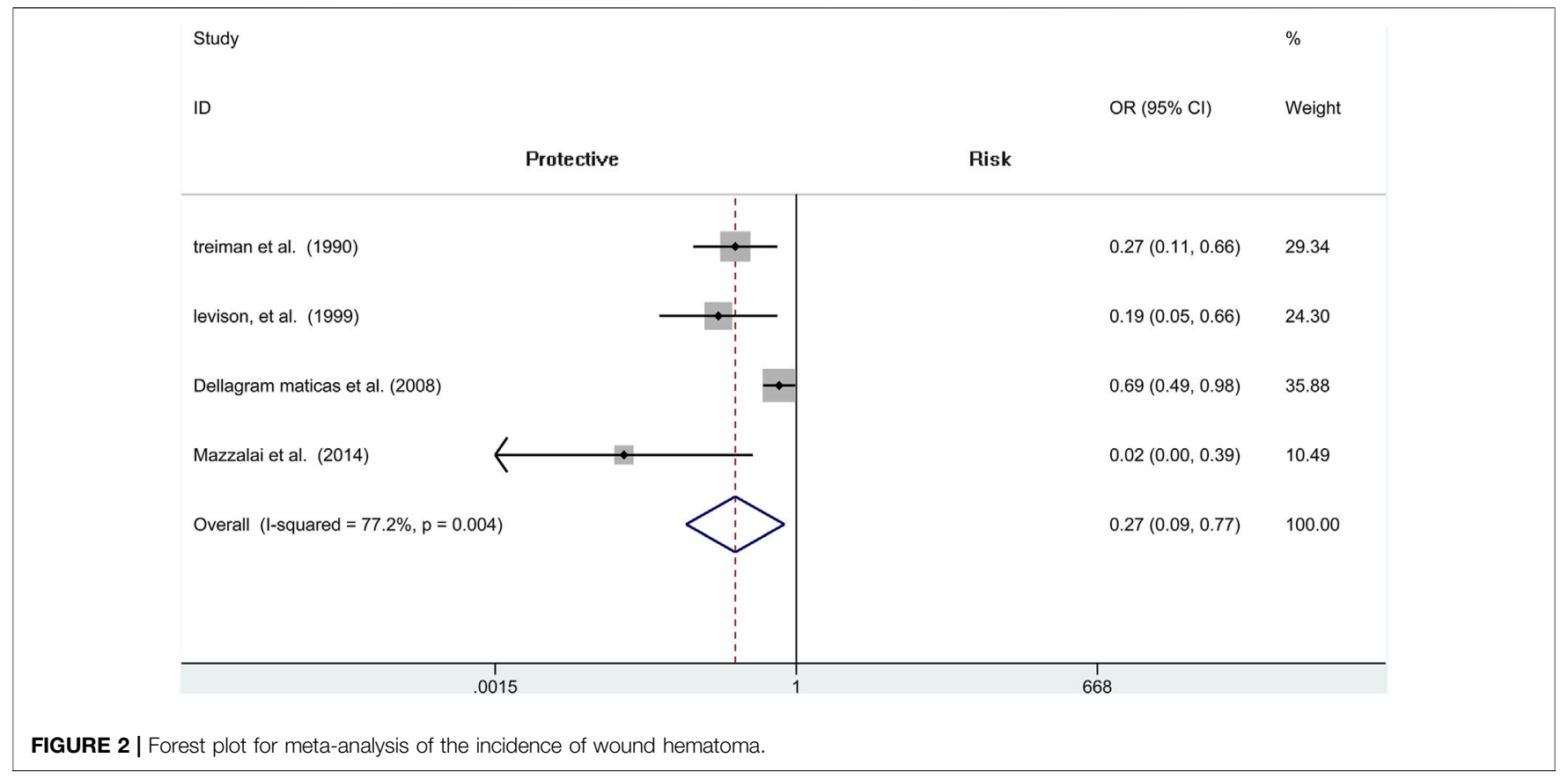

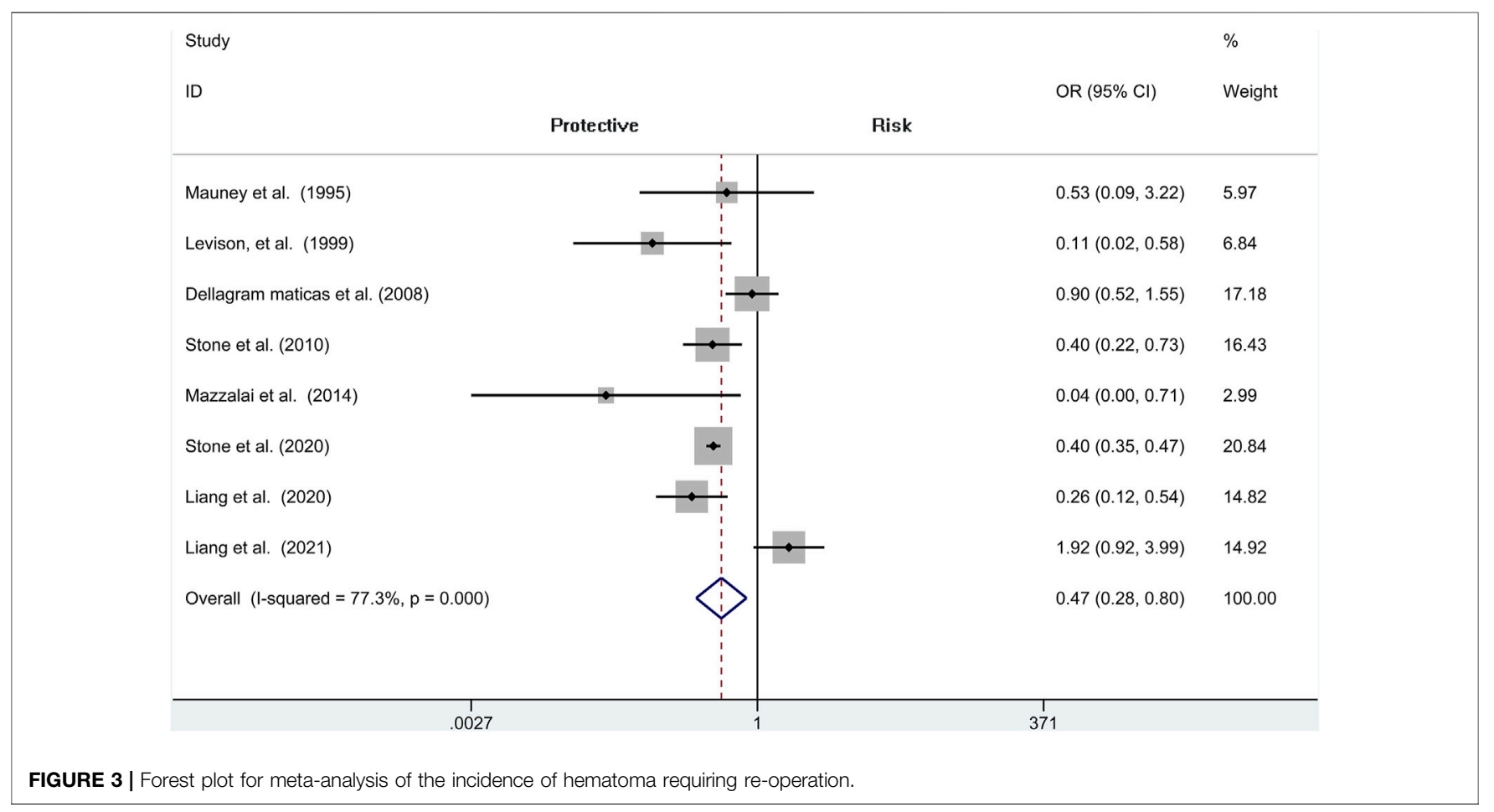

sensitivity analysis was performed to reveal that the heterogeneity was decreased by deleting the study conducted by Dellagrammaticas et al. $\left(I^{2}=51.6 \%, p=0.127\right)$.

\section{Hematoma Requiring Re-operation}

Analysis of risk of hematoma requiring re-operation between the protamine and no-protamine groups is provided in eight studies. The proportion estimated in protamine and noprotamine groups is $0.7 \%$ (409 of 60,013 ) versus $1.8 \%$ (591 of 32,714$)$. However, a significant heterogeneity was observed, and a random effects model was used $\left(I^{2}=77.3 \%, p<0.001\right)$. A specific OR of 0.475 ( $95 \% \mathrm{CI}=0.282$ to $0.798, p=0.005$; Figure 3) is obtained, suggesting that the incidence of hematoma requiring re-operation is significantly lower than 


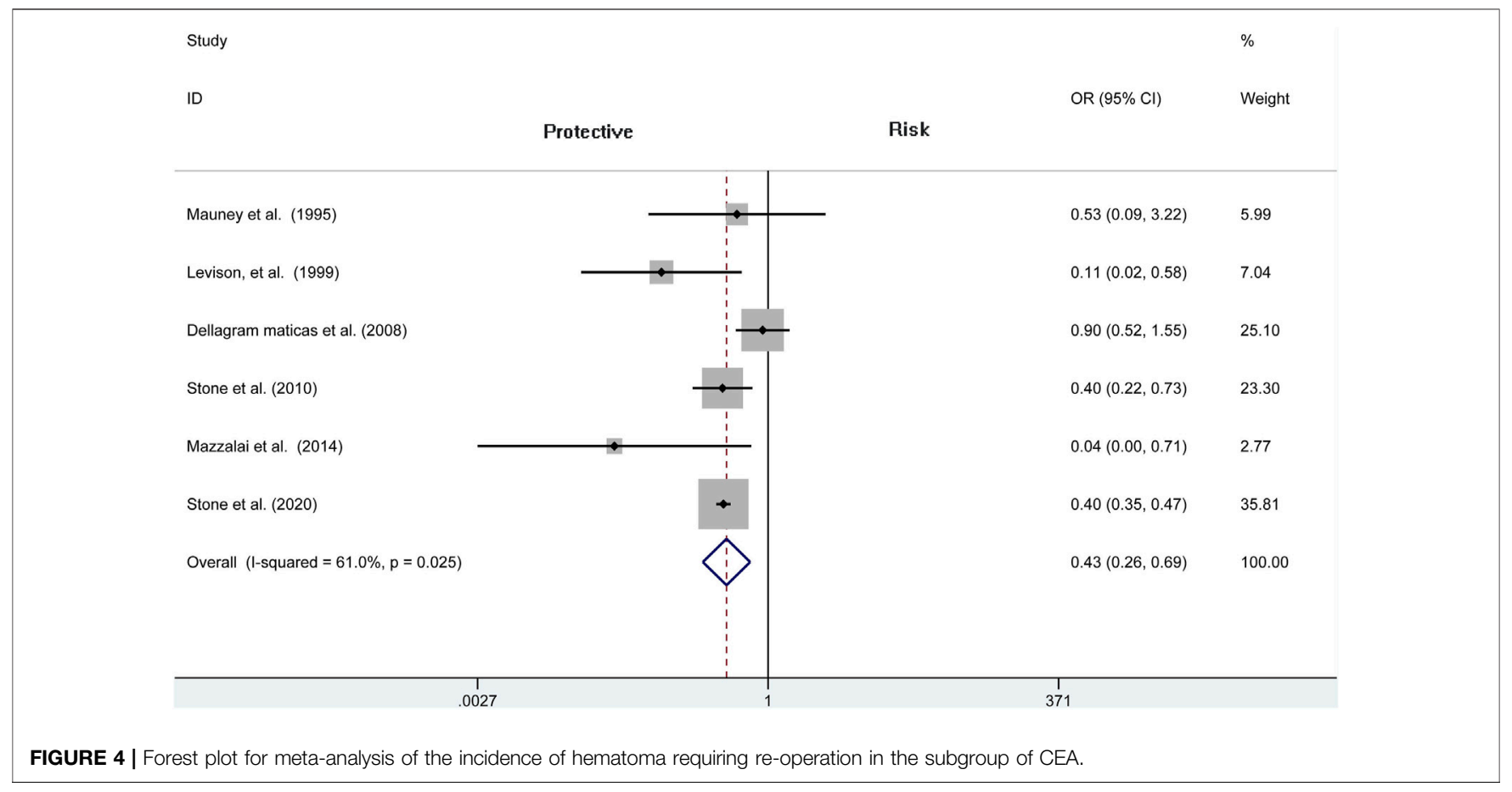

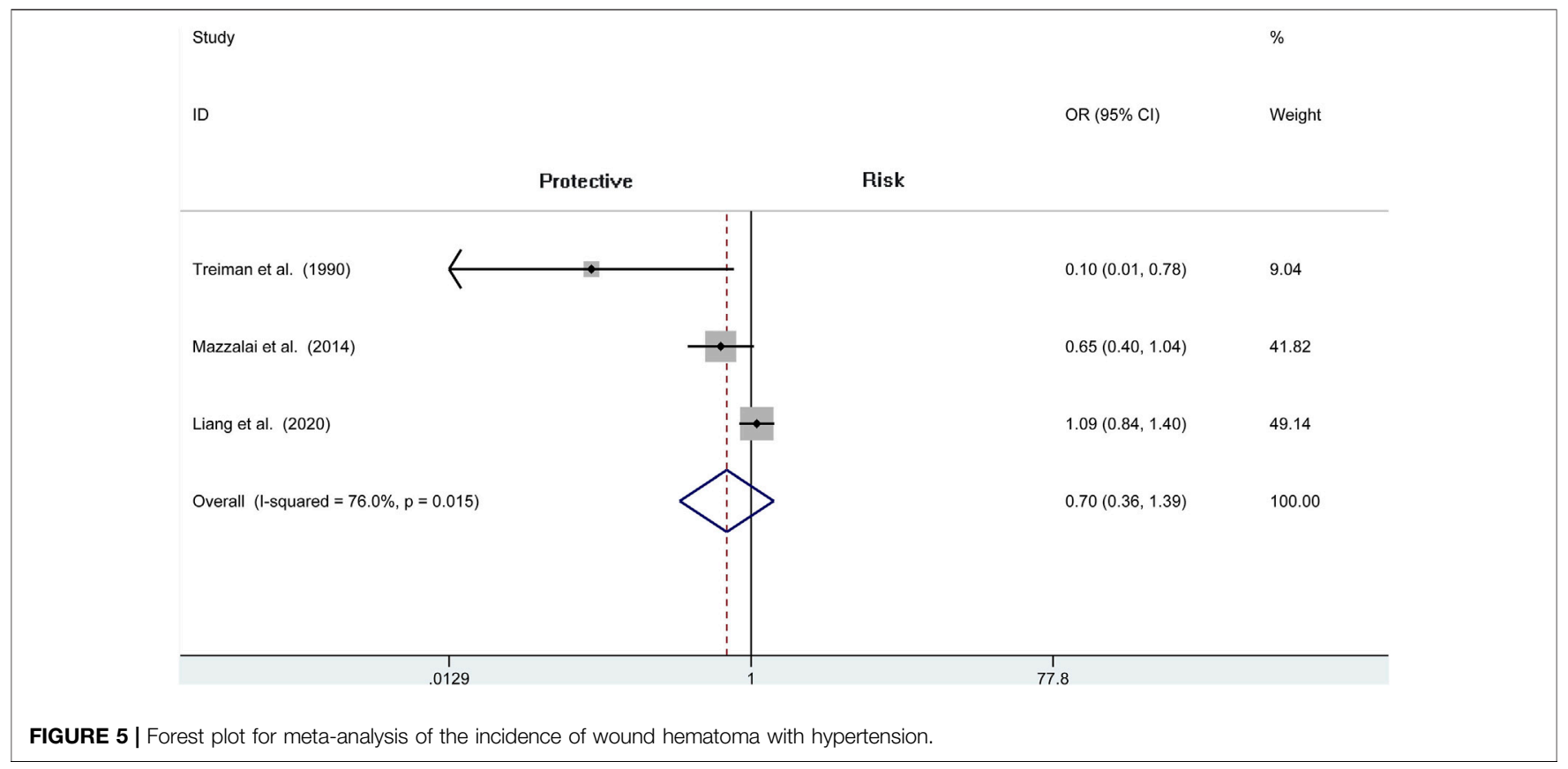

patients without protamine. Given a significant heterogeneity, we conducted a subgroup analysis, and the results showed that the heterogeneity was decreased $\left(I^{2}=61 \%, p=0.025\right)$ and that there is also a significant difference in the subgroup of CEA between the two groups $(\mathrm{OR}=0.429,95 \% \mathrm{CI}=0.265$ to 0.694 , $p=0.001$; Figure 4). In addition, we perform a sensitivity analysis and found that the heterogeneity was significantly decreased by deleting the study conducted by Dellagrammaticas et al. $\left(I^{2}=17.7 \%, p=0.302\right)$.

\section{Wound Hematoma With Hypertension}

Three articles $(N=4,078)$ report the wound hematoma with hypertension. This analysis does not find a significant difference between the two groups ( $\mathrm{OR}=0.704,95 \% \mathrm{CI}=0.358$ to $1.388, p=$ 0.311 ; Figure 5), whereas a high heterogeneity is presented in these studies $\left(I^{2}=76 \%, p=0.015\right)$. Therefore, we also analyze the subgroup of CEA and reveal that there is no difference among the protamine and no-protamine groups $(\mathrm{OR}=0.333,95 \% \mathrm{CI}=$ 0.057 to $1.959, p=0.224$; Figure 6). However, a high heterogeneity in 


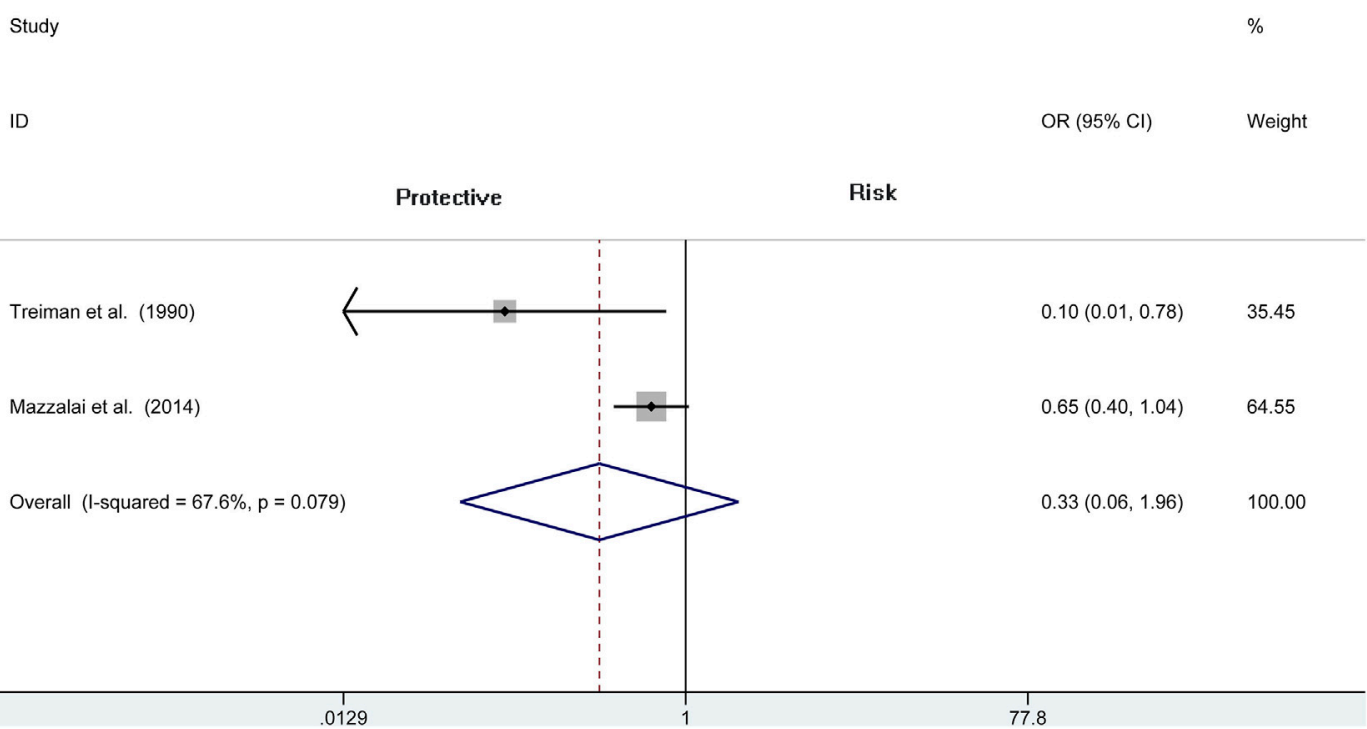

FIGURE 6 | Forest plot for meta-analysis of the incidence of wound hematoma with hypertension in the subgroup of CEA.

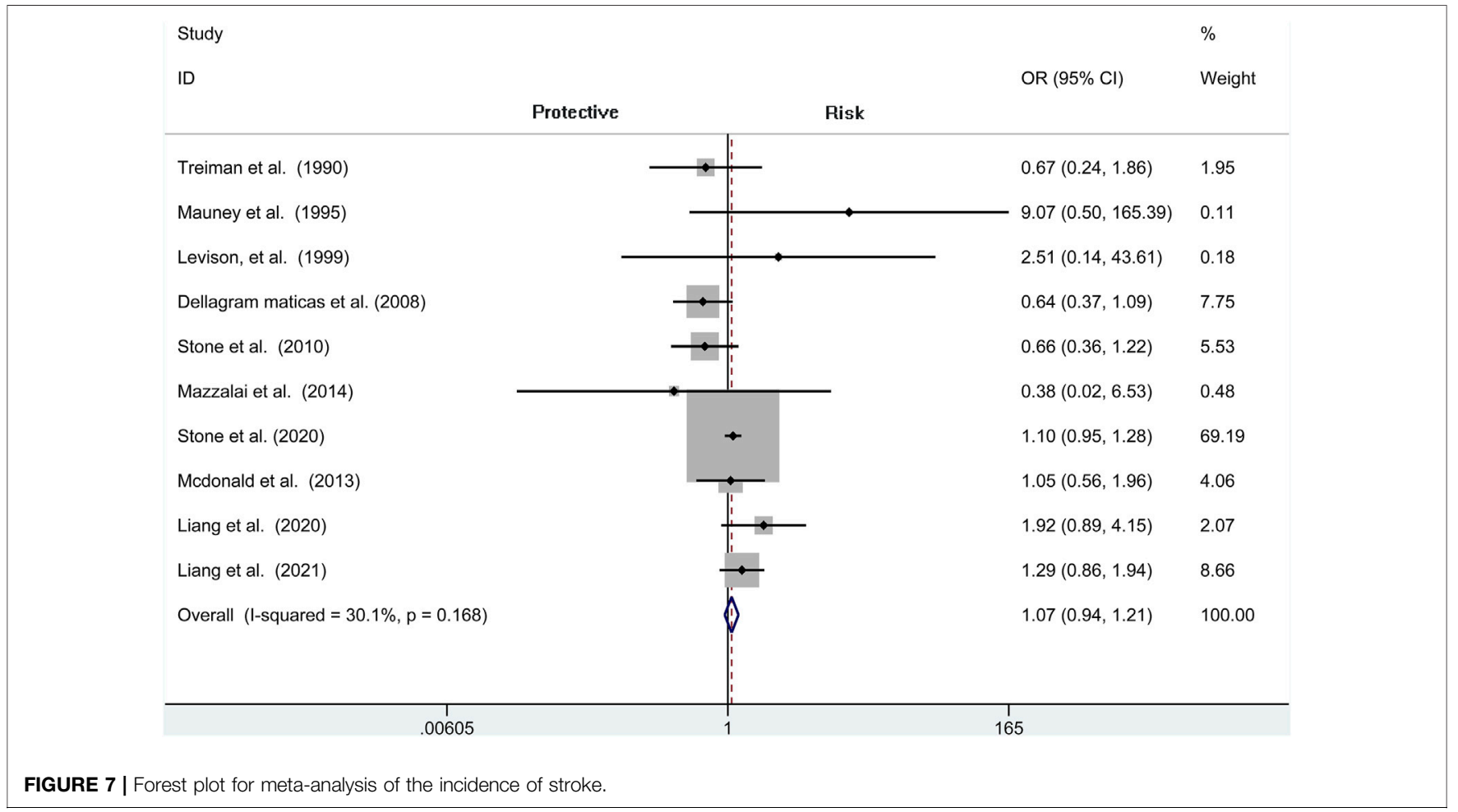

these studies was also observed $\left(I^{2}=67.6 \%, p=0.079\right)$. Moreover, we performed a sensitivity analysis, but no significant difference was revealed in the changes of heterogeneity.

\section{Stroke}

A total of seven independent studies compare protamine with no protamine in participants undergoing CEA, while three studies include participants with carotid stenting. There is no significant heterogeneity among these studies $\left(I^{2}=30.1 \%, p=0.168\right)$. We think that patients treated with protamine did not have a lower rate of stroke than those treated with no protamine $(\mathrm{OR}=1.071$, $95 \% \mathrm{CI}=0.944-1.214, p=0.286$, Figure 7$)$. In the subgroup of CEA, there is also no significant difference between the two groups $(\mathrm{OR}=1.029,95 \% \mathrm{CI}=0.897$ to $1.180, p=0.687$; Figure 8). 


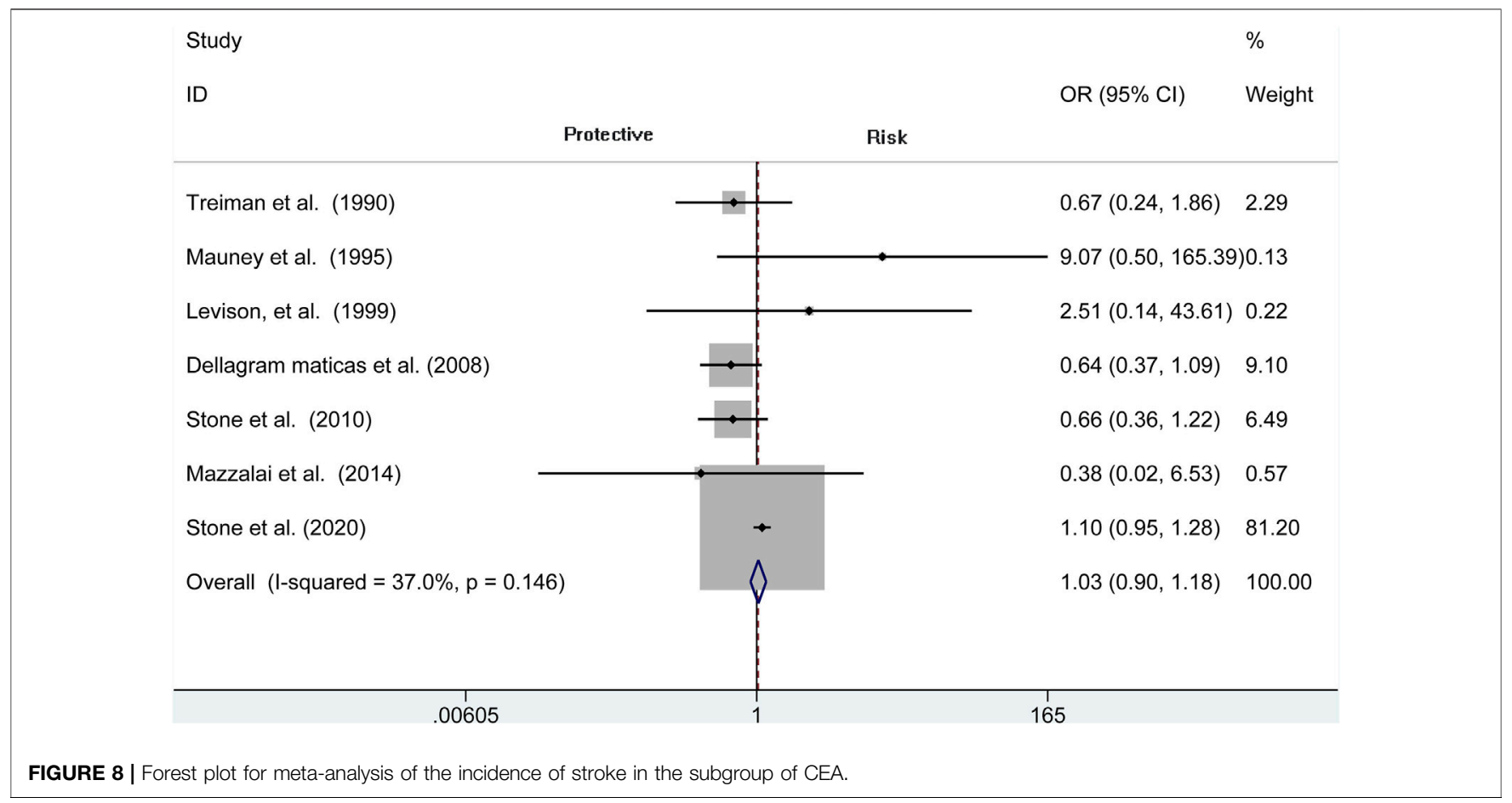

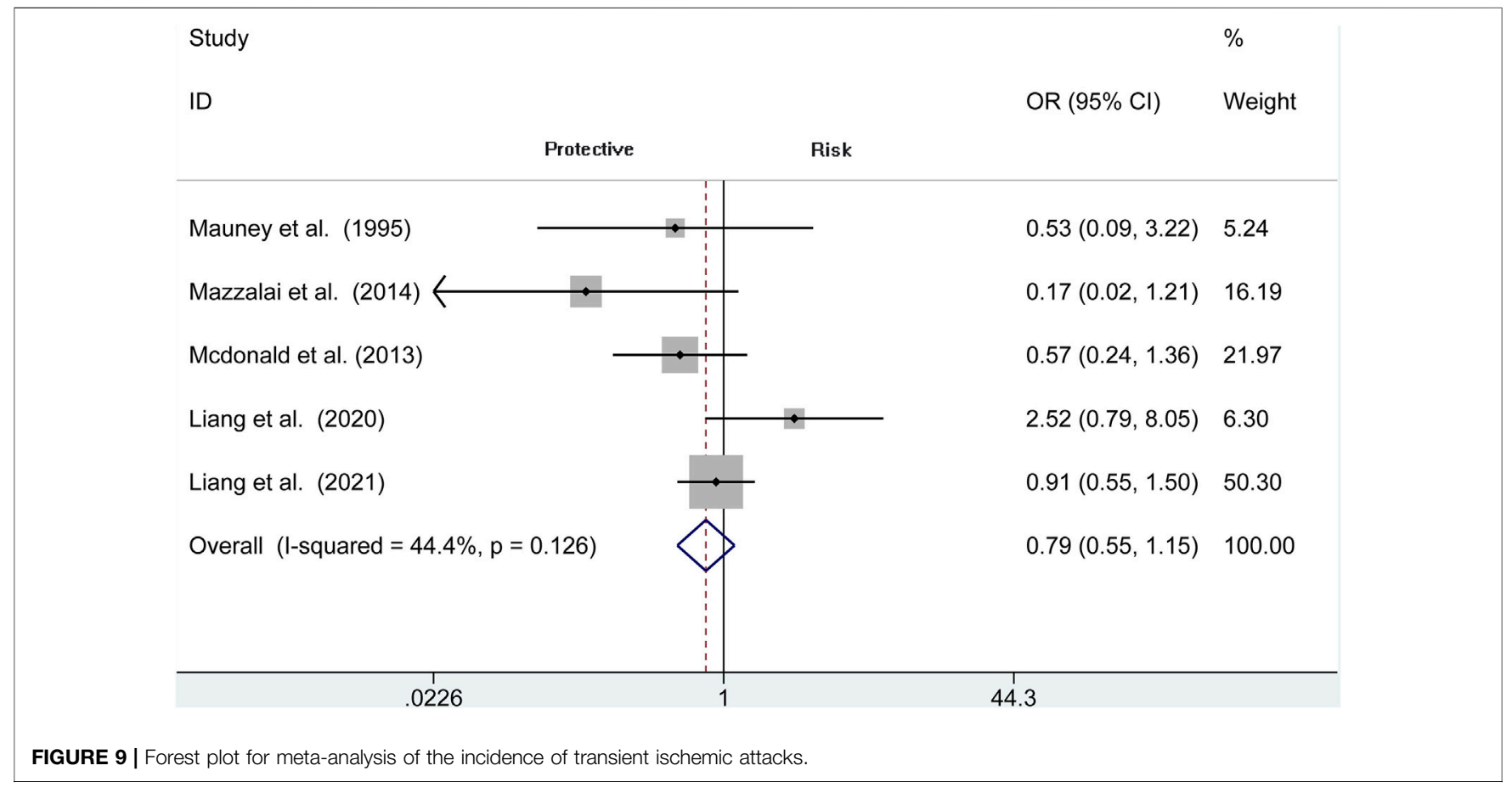

\section{Transient Ischemic Attacks}

The risk of TIA is reported in 5 observational studies $(N=$ 9,441). Perioperative TIA occurred in the protamine (50 of $4,193,1.2 \%$ ) and no-protamine group (91 of 5,248, 1.7\%). No evidence of significant heterogeneity is revealed in these studies $\left(I^{2}=44.4 \%, p=0.126\right)$. The overall analysis does not prove an apparent difference in TIA rates between protamine and no-protamine groups $(\mathrm{OR}=0.793,95 \% \mathrm{CI}$ $=0.546$ to $1.151, p=0.222$; Figure 9). However, a difference is presented in the subgroup of CEA among these two groups $(\mathrm{OR}=0.255,95 \% \mathrm{CI}=0.068$ to $0.947, p=0.041$; Supplementary Figure S1). 


\section{Myocardial Infarction (MI)}

The MI is reported in seven studies. In these publications, 60,030 and 33,072 patients are enrolled in the protamine and noprotamine groups, respectively. The results reveal that there is no significant difference in occurrence of $\mathrm{MI}(\mathrm{OR}=0.935,95 \% \mathrm{CI}$ $=0.797$ to $1.096, p=0.408$, Supplementary Figure S2) and between-study heterogeneity is low $\left(I^{2}=0.0 \%, p=0.446\right)$. Similarly, we find that there is also no difference among protamine and no-protamine patients in the subgroup of CEA $(\mathrm{OR}=0.902,95 \% \mathrm{CI}=0.764$ to $1.065, p=0.224$, Supplementary Figure S3).

\section{Death}

Seven publications report post-operative death enrolling 87,164 patients. No significant difference in mortality between the protamine and no-protamine group is seen ( $\mathrm{RD}=0.000,95 \%$ $\mathrm{CI}=-0.001$ to $0.001, p=0.877$, Supplementary Figure S4). The same result is found in the subgroup of CEA as well $(\mathrm{RD}=0.000$, $95 \%$ CI $=-0.001$ to $0.001, p=0.878$, Supplementary Figure S5).

\section{DISCUSSION}

Carotid artery stenosis is a major cause of stroke, which is the most common risk for long-term disability. Surgical treatment (carotid recanalization) is considered significantly meaningful for artery stenosis. Even though it reduces the risk of stroke, it carries a risk of hematoma (Rerkasem et al., 2020). Protamine, which was primarily isolated from salmon fish sperm, is a small, argininerich, positively charged protein with similarities to histones in that it has a role in stabilizing DNA in the sperm head (Bakchoul et al., 2016; Boer et al., 2018). It is adopted in a variety of vascular and cardiac procedures to reserve systemic heparin anticoagulation (Phair et al., 2020), especially for carotid recanalization (Lamanna et al., 2019). However, this inevitably leads to bleeding and then further cause major or minor strokes, myocardial infarction, or death (Yuan et al., 2018). Herein, we wonder whether protamine did affect the efficiency and safety of carotid recanalization and try to illustrate its safety and effectiveness in this surgery. Our results demonstrate that protamine can reduce the risk of bleeding without increasing the risk of having other complications.

Reoperation or reintervention is needed if bleeding happened during carotid recanalization, which is associated with the chance of perioperative stroke, MI, or even death. Miklosz et al. (2019) measured the platelet numbers, collagen-induced aggregation, etc. in blood extracted from mice and rats and then furthermore found that protamine has a short-term antiplatelet activity. In 2016, Kakisis et al. (2016) did a meta-analysis showing that the incidence of wound hematoma in the no-protamine group was $6 \%$, whereas only $1.7 \%$ happened in the protamine group. They finally indicated that protamine significantly reduced the risk of wound hematoma by $64 \%$ without increasing the risk of postoperative stroke. Similarly, our analysis found that the incidence of wound hematoma in the protamine group is $3.8 \%$ (57 of 1,488$)$, which is lower than that in the no-protamine group $(9.5 \%, 305$ of $3,218)$. Furthermore, a specific OR of 0.475 (95\% CI =
$0.282-0.798, p=0.005)$ was obtained, suggesting that the rates of hematoma requiring re-operation was lower than that in patients without protamine. However, we thought the high rates of wound hematoma may be related to a higher risk of hypertension, but there is no difference presented in the two groups $(\mathrm{OR}=0.704,95 \% \mathrm{CI}=0.358-1.388, p=0.311)$. We cannot distinguish whether this result is directly related to protamine use. As far as we know, protamine is a multi-cation strong alkaline polypeptide, which can combine with the glucosaminoglycan of heparin to form a stable complex and inhibit the activity of antithrombin, thus counteracting the anticoagulant effect of heparin and playing the effect of hemostasis. Protamineinduced circulatory changes have been demonstrated by Jastrzebski et al. (Cho et al., 2012), who explicated the role of it by endogenously liberating vasoactive substances.

Cerebral recanalization therapy, either intravenous thrombolysis or mechanical thrombectomy, improves the outcomes of patients with artery stenosis (Zhang et al., 2019), which exerts an increased impact on ischemic diseases. However, some complications involving ischemic injuries such as stroke, TIA, and MI sometimes inevitably followed. We included these three complications in our observations. One study had 365 patients who were subjected to 407 recanalization; $365(89.6 \%)$ received protamine and 42 (10.4\%) patients did not; $2.5 \%$ (10/407) happened postoperatively in the protamine group. This meta-analysis did not find an association between protamine and stroke (Levison et al., 1999). Likely, in our research, even though the stroke rates were slightly lower than without protamine, our results did not obtain statistical significance $(\mathrm{OR}=1.071$, $95 \% \mathrm{CI}=0.944$ to $1.214, p=0.286$ ), the same result as TIA. Even though protamine did not affect the incidence of stroke and TIA by multivariate analysis, the risk of MI has also been studied extensively. In light of the $0.7 \%$ rate of MI in our study with protamine showing no significant difference $(\mathrm{OR}=0.935,95 \%$ $\mathrm{CI}=0.797$ to $1.096, p=0.408$ ). Furthermore, we should note that the protamine did not change the rate of death among these two groups $(\mathrm{RD}=0.000,95 \% \mathrm{CI}=-0.001$ to $0.001, p=0.877$ ). Meanwhile, other studies related to this topic did not find an association between protamine and stroke, TIA, MI, and death. We suspect that there may be a certain stimulation factor of protamine that causes a reduction in bleeding.

Our research has several limitations. The dosage of protamine was not standardized, which may confound the outcomes. Besides the primary inclusion and exclusion criteria, the characteristics of the participants were a little different from each other, potentially causing bias. The number of recent and high-quality studies was too small. Additionally, some heterogeneity was found among included trials due to the different study protocols, patient characteristics, and definitions of clinical endpoints. Moreover, the current study is not registered and there may be a slight deviation, but we strictly followed the procedures of systematic evaluation. Finally, the exact sequence of disease for the included patients cannot be known exactly and protamine might have been administered after a complication occurred rather than before, which might have affected our results. 


\section{CONCLUSION}

This study has crucial implications. The current meta-analysis demonstrates that surgeons should consider routinely using protamine during carotid recanalization especially for CEA, due to the lower incidence of wound hematoma and hematoma requiring re-operation with its use. These findings, however, have inherent limitations, such as obvious heterogeneity and data from retrospective reviews; therefore, they cannot be regarded robust enough to provide a firm recommendation in clinical practice. With regard to the carotid artery stenting, there were fewer studies examining the effect of protamine; herein, further research is necessary to illustrate whether consistent results exist across all types of carotid revascularization.

\section{BRIEF STATEMENT}

Protamine, which was primarily isolated from salmon fish sperm, is a small, arginine-rich, positively charged protein with similarities to histones in that it has a role in stabilizing DNA in the sperm head. Despite it being adopted in a variety of vascular and cardiac procedures to reserve systemic heparin anticoagulation, especially for carotid recanalization, this inevitably leads to bleeding and then further causes major or minor strokes, myocardial infarction, or death. Herein, a comprehensive review and meta-analysis are

\section{REFERENCES}

Abbott, A. L., Paraskevas, K. I., Kakkos, S. K., Golledge, J., Eckstein, H. H., DiazSandoval, L. J., et al. (2015). Systematic Review of Guidelines for the Management of Asymptomatic and Symptomatic Carotid Stenosis. Stroke 46 (11), 3288-3301. doi:10.1161/STROKEAHA.115.003390

Al-Kassou, B., Kandt, J., Lohde, L., Shamekhi, J., Sedaghat, A., Tabata, N., et al. (2020). Safety and Efficacy of Protamine Administration for Prevention of Bleeding Complications in Patients Undergoing TAVR. JACC Cardiovasc. Interv. 13 (12), 1471-1480. doi:10.1016/j.jcin.2020.03.041

Bakchoul, T., Jouni, R., and Warkentin, T. E. (2016). Protamine (Heparin)-induced Thrombocytopenia: a Review of the Serological and Clinical Features Associated with Anti-protamine/heparin Antibodies. J. Thromb. Haemost. 14 (9), 1685-1695. doi:10.1111/jth.13405

Boer, C., Meesters, M. I., Veerhoek, D., and Vonk, A. B. A. (2018). Anticoagulant and Side-Effects of Protamine in Cardiac Surgery: a Narrative Review. $\mathrm{Br}$. J. Anaesth. 120 (5), 914-927. doi:10.1016/j.bja.2018.01.023

Cho, Y. D., Lee, J. Y., Seo, J. H., Kang, H. S., Kim, J. E., Kwon, O. K., et al. (2012). Early Recurrent Hemorrhage after Coil Embolization in Ruptured Intracranial Aneurysms. Neuroradiology 54 (7), 719-726. doi:10.1007/s00234-011-0950-3

Dellagrammaticas, D., Lewis, S. C., and Gough, M. J. (2008). Is Heparin Reversal with Protamine after Carotid Endarterectomy Dangerous? Eur. J. Vasc. Endovasc Surg. 36 (1), 41-44. doi:10.1016/j.ejvs.2008.01.021

Dharmakidari, S., Bhattacharya, P., and Chaturvedi, S. (2017). Carotid Artery Stenosis: Medical Therapy, Surgery, and Stenting. Curr. Neurol. Neurosci. Rep. 17 (10), 77. doi:10.1007/s11910-017-0786-2

Fearn, S. J., Parry, A. D., Picton, A. J., Mortimer, A. J., and McCollum, C. N. (1997). Should Heparin Be Reversed after Carotid Endarterectomy? A Randomised Prospective Trial. Eur. J. Vasc. Endovasc Surg. 13 (4), 394-397. doi:10.1016/ s1078-5884(97)80082-2

Howell, S. J. (2007). Carotid Endarterectomy. Br. J. Anaesth. 99 (1), 119-131. doi:10.1093/bja/aem137

Jaques, L. B. (1973). Protamine--antagonist to Heparin. Can. Med. Assoc. J. 108 (10), 1291-1297. necessary to illustrate the efficiency of protamine for carotid recanalization. This study demonstrated that protamine was effective in reducing hematoma without increasing the risk of having other complications.

\section{DATA AVAILABILITY STATEMENT}

The original contributions presented in the study are included in the article/Supplementary Material, further inquiries can be directed to the corresponding authors.

\section{AUTHOR CONTRIBUTIONS}

YP and WX designed and conceptualized the article. QJ and WW prepared the figures and tables. All authors significantly contributed to writing the paper and provided important intellectual content.

\section{SUPPLEMENTARY MATERIAL}

The Supplementary Material for this article can be found online at: https://www.frontiersin.org/articles/10.3389/fphar.2022.796329/ full\#supplementary-material

Kakisis, J. D., Antonopoulos, C. N., Moulakakis, K. G., Schneider, F., Geroulakos, G., and Ricco, J. B. (2016). Protamine Reduces Bleeding Complications without Increasing the Risk of Stroke after Carotid Endarterectomy: A Meta-Analysis. Eur. J. Vasc. Endovasc Surg. 52 (3), 296-307. doi:10.1016/j.ejvs.2016.05.033

Lamanna, A., Maingard, J., Barras, C. D., Kok, H. K., Handelman, G., Chandra, R. V., et al. (2019). Carotid Artery Stenting: Current State of Evidence and Future Directions. Acta Neurol. Scand. 139 (4), 318-333. doi:10.1111/ane.13062

Levison, J. A., Faust, G. R., Halpern, V. J., Theodoris, A., Nathan, I., Kline, R. G., et al. (1999). Relationship of Protamine Dosing with Postoperative Complications of Carotid Endarterectomy. Ann. Vasc. Surg. 13 (1), 67-72. doi:10.1007/s100169900222

Li, Q., Gao, Y., Xin, W., Zhou, Z., Rong, H., Qin, Y., et al. (2019). Meta-Analysis of Prognosis of Different Treatments for Symptomatic Moyamoya Disease. World Neurosurg. 127, 354-361. doi:10.1016/j.wneu.2019.04.062

Liang, P., Motaganahalli, R., Swerdlow, N. J., Dansey, K., Varkevisser, R. R. B., Li, C., et al. (2021). Protamine Use in Transfemoral Carotid Artery Stenting Is Not Associated with an Increased Risk of Thromboembolic Events. J. Vasc. Surg. 73 (1), 142-e4. doi:10.1016/j.jvs.2020.04.526

Liang, P., Motaganahalli, R. L., Malas, M. B., Wang, G. J., Eldrup-Jorgensen, J., Cronenwett, J. L., et al. (2020). Protamine Use in Transcarotid Artery Revascularization Is Associated with Lower Risk of Bleeding Complications without Higher Risk of Thromboembolic Events. J. Vasc. Surg. 72 (6), 2079-2087. doi:10.1016/j.jvs.2020.02.019

Lynch, N. P., and Kavanagh, E. G. (2016). Does Routine Reversal of Heparin with Protamine Sulphate in Patients Undergoing Carotid Endarterectomy Reduce Bleeding Complications without Leading to Increased Thromboembolic Complications? Eur. J. Vasc. Endovasc Surg. 51 (1), 150. doi:10.1016/j.ejvs. 2015.09.001

Mauney, M. C., Buchanan, S. A., Lawrence, W. A., Bishop, A., Sinclair, K., Daniel, T. M., et al. (1995). Stroke Rate Is Markedly Reduced after Carotid Endarterectomy by Avoidance of Protamine. J. Vasc. Surg. 22 (3), 264-270. ; discussion 269-70. doi:10.1016/s0741-5214(95)70140-0

Mazzalai, F., Piatto, G., Toniato, A., Lorenzetti, R., Baracchini, C., and Ballotta, E. (2014). Using Protamine Can Significantly Reduce the Incidence of Bleeding Complications after Carotid Endarterectomy without Increasing the Risk of 
Ischemic Cerebral Events. World J. Surg. 38 (5), 1227-1232. doi:10.1007/ s00268-013-2347-4

McDonald, J. S., Kallmes, D. F., Lanzino, G., and Cloft, H. J. (2013). Protamine Does Not Increase Risk of Stroke in Patients with Elective Carotid Stenting. Stroke 44 (7), 2028-2030. doi:10.1161/STROKEAHA.113.001188

Miklosz, J., Kalaska, B., Kaminski, K., Rusak, M., Szczubialka, K., Nowakowska, M., et al. (2019). The Inhibitory Effect of Protamine on Platelets Is Attenuated by Heparin without Inducing Thrombocytopenia in Rodents. Mar. Drugs 17 (9). doi:10.3390/md17090539

Mitchell-Jones, N., Gallos, I., Farren, J., Tobias, A., Bottomley, C., and Bourne, T. (2017). Psychological Morbidity Associated with Hyperemesis Gravidarum: a Systematic Review and Meta-Analysis. BJOG 124 (1), 20-30. doi:10.1111/14710528.14180

Newhall, K. A., Saunders, E. C., Larson, R. J., Stone, D. H., and Goodney, P. P. (2016). Use of Protamine for Anticoagulation during Carotid Endarterectomy: A Meta-Analysis. JAMA Surg. 151 (3), 247-255. doi:10.1001/jamasurg.2015. 3592

Patel, R. B., Beaulieu, P., Homa, K., Goodney, P. P., Stanley, A. C., Cronenwett, J. L., et al. (2013). Shared Quality Data Are Associated with Increased Protamine Use and Reduced Bleeding Complications after Carotid Endarterectomy in the Vascular Study Group of New England. J. Vasc. Surg. 58 (6), 1518-e1. doi:10. 1016/j.jvs.2013.06.064

Phair, J., Futchko, J., Trestman, E. B., Carnevale, M., Friedmann, P., Shukla, H., et al. (2020). Protamine Sulfate Use during Tibial Bypass Does Not Appear to Increase Thrombotic Events or Affect Short-Term Graft Patency. Vascular 28 (6), 708-714. doi:10.1177/1708538120924149

Rerkasem, A., Orrapin, S., Howard, D. P., and Rerkasem, K. (2020). Carotid Endarterectomy for Symptomatic Carotid Stenosis. Cochrane Database Syst. Rev. 9, CD001081. doi:10.1002/14651858.CD001081.pub4

Setacci, C., Sterpetti, A., and de Donato, G. (2018). Introduction: Carotid Endarterectomy versus Carotid Stenting-A Never-Ending story. Semin. Vasc. Surg. 31 (1), 1-3. doi:10.1053/j.semvascsurg.2018.03.001

Sokolowska, E., Kalaska, B., Miklosz, J., and Mogielnicki, A. (2016). The Toxicology of Heparin Reversal with Protamine: Past, Present and Future. Expert Opin. Drug Metab. Toxicol. 12 (8), 897-909. doi:10.1080/17425255.2016.1194395

Spence, J. D., Song, H., and Cheng, G. (2016). Appropriate Management of Asymptomatic Carotid Stenosis. Stroke Vasc. Neurol. 1 (2), 64-71. doi:10. 1136/svn-2016-000016

Spiliopoulos, S., Vasiniotis Kamarinos, N., Reppas, L., Palialexis, K., and Brountzos, E. (2019). Carotid Artery Stenting: an Update. Curr. Opin. Cardiol. 34 (6), 616-620. doi:10.1097/HCO.0000000000000679
Stone, D. H., Giles, K. A., Kubilis, P., Suckow, B. D., Goodney, P. P., Huber, T. S., et al. (2020). Protamine Reduces Serious Bleeding Complications Associated with Carotid Endarterectomy in Asymptomatic Patients without Increasing the Risk of Stroke, Myocardial Infarction, or Death in a Large National AnalysisStroke, Myocardial Infarction, or Death in a Large National Analysis. Eur. J. Vasc. Endovasc Surg. 60 (6), 800-807. doi:10.1016/j.ejvs. 2020.08.047

Stone, D. H., Nolan, B. W., Schanzer, A., Goodney, P. P., Cambria, R. A., Likosky, D. S., et al. (2010). Protamine Reduces Bleeding Complications Associated with Carotid Endarterectomy without Increasing the Risk of Stroke. J. Vasc. Surg. 51 (3), 559-e1. 564 el. doi:10.1016/j.jvs.2009.10.078

Treiman, R. L., Cossman, D. V., Foran, R. F., Levin, P. M., Cohen, J. L., and Wagner, W. H. (1990). The Influence of Neutralizing Heparin after Carotid Endarterectomy on Postoperative Stroke and Wound Hematoma. J. Vasc. Surg. 12 (4), 440-446. doi:10.1016/0741-5214(90)90046-d

Yip, H. K., Sung, P. H., Wu, C. J., and Yu, C. M. (2016). Carotid Stenting and Endarterectomy. Int. J. Cardiol. 214, 166-174. doi:10.1016/j.ijcard.2016.03.172

Yuan, G., Zhou, S., Wu, W., Zhang, Y., Lei, J., and Huang, B. (2018). Carotid Artery Stenting versus Carotid Endarterectomy for Treatment of Asymptomatic Carotid Artery Stenosis. Int. Heart J. 59 (3), 550-558. doi:10.1536/ihj.17-312

Zhang, Z., Pu, Y., Mi, D., and Liu, L. (2019). Cerebral Hemodynamic Evaluation after Cerebral Recanalization Therapy for Acute Ischemic Stroke. Front. Neurol. 10, 719. doi:10.3389/fneur.2019.00719

Conflict of Interest: The authors declare that the research was conducted in the absence of any commercial or financial relationships that could be construed as a potential conflict of interest.

Publisher's Note: All claims expressed in this article are solely those of the authors and do not necessarily represent those of their affiliated organizations, or those of the publisher, the editors, and the reviewers. Any product that may be evaluated in this article, or claim that may be made by its manufacturer, is not guaranteed or endorsed by the publisher.

Copyright (c) 2022 Pan, Zhao, Yang, Jiao, Wei, Ji and Xin. This is an open-access article distributed under the terms of the Creative Commons Attribution License (CC $B Y)$. The use, distribution or reproduction in other forums is permitted, provided the original author(s) and the copyright owner(s) are credited and that the original publication in this journal is cited, in accordance with accepted academic practice. No use, distribution or reproduction is permitted which does not comply with these terms. 